DOI: http://dx.doi.org/10.18764/2358-4319.v13n1 p245-264

\title{
Influência da cultura local no processo de ensino e aprendizagem da comunidade quilombola Salinas
}

\author{
Neilany Araújo de Sousa' \\ Lucinete Aragão Mascarenhas e Silva²
}

\section{RESUMO}

O principal aporte desta pesquisa é mostrar alguns fatores que podem levar a comunidade quilombola a lutar por seus direitos. Com essa finalidade, foi realizada uma pesquisa exploratória com o coordenador da comunidade para saber a opinião de cada um sobre o que levou a comunidade se tornar quilombola. Além destes procedimentos realizou-se pesquisa também bibliográfica para fundamentar o trabalho observado a visão de diferentes autores. Estudos que abordam sobre a comunidade quilombola de Salinas através de seus movimentos sociais, sua luta pelo reconhecimento de seus valores e contra toda e qualquer forma de racismo na construção de uma nação justa e igualitária, para todos que nela vivem sem preconceito.

Palavras-chave: Educação Quilombola. Cultura. Ensino.

\section{Influence of local culture on the teaching and learning process of the quilombola community Salinas}

\section{ABSTRACT}

The main contribution of this research is to show some factors that can lead the quilombola community to fight for their rights. For this purpose, an exploratory survey was carried out with the community coordinator to find out what each one thought about what led the community to become quilombola. In addition to these procedures, a bibliographical research was also carried out to substantiate the work observed in the view of different authors. Studies that address the quilombola community of Salinas through their social movements, their struggle for

1 Mestre em Ciências da Educação pela Faculdade Anne Sullivan University Inglaterra. Professora da Universidade Estadual do Piauí - UESPI. Email: neizinhasousa@hotmail.com

2 Doutora em Ciências da Educação, UAL, Portugal. Professora e coordenadora pedagógica Secretaria da Educação do estado do Piauí. Email. doutorandamascarenhas@hotmail.com 
the recognition of their values and against any and all forms of racism in the construction of a just and egalitarian nation, for all who live there without prejudice.

Keywords: Quilombola Education. Culture. Teaching.

\section{Influencia de la cultura local en el proceso de enseñanza y aprendizaje de la comunidad de quilombola Salinas}

\section{RESUMEN}

La principal contribución de esta investigación es mostrar algunos factores que pueden llevar a la comunidad quilombola a luchar por sus derechos. Para este propósito, se realizó una encuesta exploratoria con el coordinador de la comunidad para averiguar qué pensaba cada uno sobre lo que llevó a la comunidad a convertirse en quilombola. Además de estos procedimientos, también se llevó a cabo una investigación bibliográfica para corroborar el trabajo observado a juicio de diferentes autores. Estudios que abordan la comunidad quilombola de Salinas a través de sus movimientos sociales, su lucha por el reconocimiento de sus valores y contra cualquier forma de racismo en la construcción de una nación justa e igualitaria, para todos los que viven allí sin prejuicios.

Palabras clave: Educación. Quilombola. Cultura Docencia

\section{Introdução}

Questionar a cultura ou impacto cultural sem discutir as causas e efeitos locais é impreciso. O dinamismo da sociedade é importante para alcançar os objetivos ao longo da vida. O desenvolvimento cultural, intelectual e profissional acompanhado da criatividade humana são resultados dos impactos ocasionados pelo mundo globalizado o que oferece como resultados: competitividade, desemprego, individualismo, entre outros fatos aqui não citados para a classe favorecida.

Nesse sentido, este trabalho visa abordar uma análise discursiva da comunidade quilombola de Salinas do município de Campinas do Piauí. Para compreender melhor alguns aspectos culturais, é necessário ter um embasamento sobre: o que é? Como se dão as interações sociais? Que sistema de valores predomina? Como se dá a relação da comunidade com a escola? 
A pesquisa apresenta aspectos empíricos de conversa informal com o coordenador da comunidade quilombola de Salinas do município de Campinas do Piauí; abordam também opiniões de alguns teóricos a respeito da comunidade. Portanto, a investigação é de caráter qualitativo, com enfoques interpretativos com base nas características apontadas nos dados obtidos, por exigir observações prolongadas e rigorosas do campo da pesquisa.

O recurso de coleta utilizado foi a entrevista, fundamentada em um roteiro estruturado elaborado pelas pesquisadoras e com reforço de um gravador de voz, objetivando a integridade dos depoimentos. Optamos por este método por proporcionar autonomia aos entrevistados ao serem expostos como sujeitos no estudo. Utilizou-se também de um documentário exibido pelo coordenador entrevistado, não estruturado com o grupo quilombola da própria comunidade enfatiza e confronta aspectos que pretende se observar. Utilizou a técnica da observação orientada, ou seja, a observação de dados foi centrada em pontos significativos da ação da pesquisa.

A demanda da comunidade quilombola de Salinas afro-brasileira por reconhecimento, valorização e afirmação de direitos no que diz respeito à educação, passou a ser particularmente apoiada com a promulgação da Lei 10.639/2003, que alterou a Lei 9.394/1996, estabelecendo a obrigatoriedade do ensino de história e cultura afro-brasileiras e africanas.

Reconhecimento implica justiça e igualdade de direitos sociais, civis, culturais e econômicos, bem como valorização da diversidade daquilo que distingue os negros das outras etnias que compõem a população brasileira. E isto requer mudança nos discursos, raciocínios, lógicas, gestos, posturas, e o tratamento para com as pessoas negras. É necessário conhecer sua história e cultura, buscando especificamente desconstruir o mito da democracia racial na sociedade brasileira; mito este que difunde a crença de que, se os negros não atingem os mesmos patamares que os não negros por falta de competência ou de interesse, desconsiderando as desigualdades seculares que a estrutura social hierárquica cria com prejuízos para os negros.

Cabe ao Estado promover e incentivar políticas de reparação, no que cumpre ao disposto na Constituição Federal, art. 205, que assinala o dever do Estado de garantir indistintamente, por meio da educação, 
iguais direitos para o pleno desenvolvimento de todos e de cada um, como pessoa, cidadão ou profissional.

A demanda por reparações visa a que o Estado e a sociedade tomem medidas para compensar os descendentes de africanos negros, dos danos psicológicos, materiais, sociais, políticos e educacionais sofridos sob o regime escravista, bem como em virtude das políticas explícitas ou tácitas de branqueamento da população, de manutenção de privilégios exclusivos para grupos com poder de governar e de influir na formação de políticas, no pós-abolição. Visa também que tais medidas se concretizem em iniciativas de combate ao racismo e todo modo de discriminações.

É necessário sublinhar que tais políticas têm como objetivo garantir os direitos dos negros, bem como de todos os cidadãos brasileiros, de cursarem cada um dos níveis de ensino, em escolas devidamente instaladas e equipadas, orientadas por profissionais qualificados para o ensino das diferentes áreas de conhecimentos; com formação para lidar com tensas relações produzidas pelo racismo e discriminações, sensíveis e capazes de conduzir a reeducação das relações entre diferentes grupos étnico-raciais, ou seja, entre descendentes de africanos, de europeus, de asiáticos e povos indígenas. Estas condições materiais das escolas e de formação de professores são indispensáveis para uma educação de qualidade.

Políticas de reparações voltadas para a educação dos negros devem oferecer garantias a essa população de ingresso, permanência e sucesso na educação escolar, de valorização do patrimônio histórico-cultural afro-brasileiro, de aquisição das competências e dos conhecimentos tidos como indispensáveis para a continuidade nos estudos, de condições para alcançar todos os requisitos, tendo em vista a conclusão de cada um dos níveis de ensino, bem como para atuar como cidadãos responsáveis e participantes, além de desempenhar com qualificação sua profissão.

Assim sendo, os sistemas de ensino e estabelecimentos de diferentes níveis converterão as demandas dos afro-brasileiros em políticas públicas de Estado ou institucionais, ao tomarem decisões e iniciativas com vista a reparações, reconhecimento e valorização da história e cultura dos afro-brasileiros. Dessa forma visam constituir programas de ações afirmativas, medidas estas que devem ser coerentes com o objetivo da escola, e que sejam compartilhados a todos os envolvidos no processo de ensino aprendizagem. 


\section{Comunidades quilombolas - processo histórico}

Quilombo, tão incompreendido e tão vivenciado por milhões de brasileiros significa habitação ou acampamento na língua banto, da África Central e Centro-Ocidental. No período do Império Ultramarino Português, a legislação definia quilombo como lugares onde se escondiam dois ou mais escravos fugitivos.

Os "mocambos", "quilombos", "comunidades negras rurais" e "terras de preto" são as nomenclaturas dadas a essa área de resistência. Tudo indica que a maioria das comunidades quilombola brasileiras formou-se após a Abolição da Escravidão (1888). Quando o decreto foi expedido, grande parte dos negros não tinha mais onde ficar, não havia trabalho e não havia perspectiva de integração à sociedade brasileira, muitas famílias dirigiram-se para áreas onde já existiam quilombos, migraram para os grotões, para as terras desabitadas ou para as margens das fazendas, outras comunidades são continuidades de quilombos formados nos períodos colonial e imperial.

Atualmente temos comunidades que desenvolveram práticas de resistência ao manter e reproduzir suas próprias maneiras de viver em um espaço determinado. O quilombo era um lugar de transição da condição de escravo para a de camponês livre.

A antropóloga da Universidade Federal de São Paulo explica que as comunidades remanescentes de quilombo são grupos sociais cuja identidade étnica os distingue do restante da sociedade. Ela define identidade étnica como um processo de autoidentificação bastante dinâmico, que não se reduz a elementos materiais ou traços biológicos distintivos, como cor da pele, por exemplo. Em outra colocação ela define identidade étnica como a identidade étnica é a base para a forma de organização dos grupos sociais. Esta identidade é a soma de múltiplos fatores, que podem ser uma ancestralidade comum, formas de organização política e elementos linguísticos e religiosos compartilhados (PERUTTI, 2009).

Portanto, o termo quilombo consiste em grupos que desenvolveram práticas cotidianas de resistência na manutenção e reprodução de seus modos de vida característicos e na consolidação de um território próprio. A identidade desses grupos também não se define pelo tamanho e número de seus membros, mas pelas experiências vividas e as versões compartilhadas de sua trajetória comum e da continuidade enquanto grupo. 
Nesse sentido, a Instrução Normativa $n^{\circ}$ 16, de 24 de março de 2004, traz:

Consideram-se remanescentes das comunidades dos quilombos, os grupos étnico raciais, segundo critérios de auto atribuição, com trajetória histórica própria, dotados de relações territoriais específicas, com presunção de ancestralidade negra relacionada com a resistência à opressão histórica sofrida. (BRASIL, 2004)

O Brasil é um país caracterizado por profundas desigualdades sociais, onde a maioria da população não tem acesso a serviços essenciais que possam garantir sua sobrevivência. Infelizmente, esta maioria que sofre as consequências das mazelas sociais desse país é de descendência africana. Os negros são a maioria dos desempregados, analfabetos, os que menos tempo permanecem nas escolas e constituem a maioria das vítimas da violência policial. Esse quadro é decorrente do processo histórico brasileiro, pois os negros foram escravizados durante séculos e, logo após o fim da escravidão legal, foram colocados à margem do desenvolvimento econômico e social. O Brasil possui hoje 3524 comunidades quilombolas mapeadas pela Fundação Cultural Palmares, cerca de $50 \%$ estão no Nordeste.

Nas margens da exclusão no Brasil, os quilombolas ocupam o primeiro lugar. Uma população remanescente do passado escravista brasileiro, que ainda se ressente do fato de vivenciar no dia a dia as consequências de um imenso prejuízo social. Livres desde o século XIX, mas sem condições de viver dignamente. Isoladas em terras da zona rural, comunidades quilombolas levam vida sem direito à água, comida, energia elétrica e saneamento básico. (BESSA, 2010)

O poeta Jorge de Lima desenhou o lado negativo desse processo da modernidade:

Dividamos o mundo em duas partes iguais: uma para portugueses, outra para espanhóis: vêm quinhentos mil escravos no bojo das naus: a metade morreu na viagem do oceano.

E segue:

Dividamos o mundo entre as pátrias.

Vêm quinhentos mil escravos no bojo das guerras:

A metade morreu nos campos de batalha.

Dividamos o mundo entre as máquinas: 
Vêm quinhentos mil escravos no bojo das fábricas,

A metade morreu na escuridão, sem ar. (LIMA, 1935, P. 25)

O sociólogo e diretor executivo do centro de estatísticas religiosas e investigações sociais - CERIS, Luís Alberto Gomes de Sousa, fez uma versão do poema de Jorge de Lima, até os dias atuais.

Dividamos o mundo globalizado entre o capital financeiro, com seus políticos servis, os economistas à frente e o FMI. Virão bem mais de quinhentos mil endividados e desempregados: Pelos ajustes eles serão jogados na exclusão sem futuro nem vez. (GOMES, 2000)

Um estudo coordenado pelo Ministério de Desenvolvimento Social e Combate à Fome afirmou que:

A maioria de $57 \%$ dos negros faz parte da classe $\mathrm{E}$ (até $\mathrm{R} \$ 768,00$ de renda familiar), é analfabeta (47\% para os chefes de famílias), não tem esgotamento sanitário (45\%) e a taxa de desnutrição chega a $15 \%$. Os menores de cinco anos "constituem um grupo de altos risco (BRASIL, 2007).

O Ministério da Saúde fez uma demonstração do índice de desnutrição "aguda", medidor da relação entre peso e altura, das crianças quilombolas. Os da classe E que formam a maioria atinge 2,6\%. No Brasil, a "aguda" está em 1,6\% (PNDS, 2008).

A preocupação com as comunidades rurais e quilombolas é algo que necessita de crescentes investimentos dados às dificuldades de acesso à informação e as impossibilidades de formação nas questões que lhes são pertinentes. O governo brasileiro defende a ideia de que a adoção de políticas públicas seja a melhor reparação a diversas situações de desigualdade e uma dessas ações afirmativas são os projetos sociais que vêm aparecendo como uma das políticas focalizadas.

Esses grupos submetidos a processos de exclusão desde os tempos coloniais, construíram territorialidade repletas de significações próprias. No caso das comunidades quilombolas a pergunta a se fazer não é por suas origens ou pelo que eles foram no passado, mas pelo que eles se tornaram no presente. (HALL, 2000, P.108)

Em um amplo conceito, políticas focalizadas visam, em sua gênese, possibilitar tratamento diferenciado favorável àqueles que, ape- 
sar das políticas universais, se mantinham dentro de baixos indicadores sociais e com isso viabilizar a elevação do estado de Bem Estar Social. Nesse sentido, as políticas focalizadas podem se contrapor às assistencialistas e também contribuir para o questionamento das desigualdades sociais. Essas ações afirmativas destinadas à população negra e depois expandidas a outras minorias são iniciativas que podem ter caráter público ou privado que se destinam a corrigir uma situação de desigualdade historicamente comprovada, e em geral se apoiam na temporalidade e nos objetivos sociais, que se visam atingir.

[...] A consolidação da visão, de cunho racista, de que "o progresso só se daria com o "embranquecimento" suscitou a adoção de medidas e ações governamentais que findaram por desenhar a exclusão, a desigualdade e a pobreza que se reproduzem no país até os dias atuais" (THEODORO, 2008, P.19).

De outro lado, "a discriminação não atua isoladamente, mas em conjunto com outros mecanismos, no processo de produção e reprodução da pobreza e de restrição de oportunidades para os negros em nosso país". (JACCOUD, 2008, p.55).

O resgate histórico e o fortalecimento da autoestima que aparece com frequência nos objetivos de propostas dos projetos sociais elaborados pelas comunidades quilombolas, são uma forma de apoiar a apropriação, pelas comunidades, de sua própria riqueza e patrimônio simbólico e concreto que as empodera e permite a ampliação de suas vozes junto aos poderes locais.

\section{Comunidade quilombola e a educação do campo - traços de uma identidade em construção}

O povo tem direito a uma educação pensada desde o seu lugar, formulada com a sua participação, vinculada à sua cultura e às suas necessidades humanas e sociais. Somos herdeiros e continuadores da luta histórica pela constituição da educação como um direito universal tendo em vista seu desenvolvimento pleno.

A educação do campo se tem desenvolvido em muitos lugares através de programas, práticas comunitárias e experiências pontuais. Não se trata de desvalorizar ou se opor a estas iniciativas, pois elas têm 
sido uma das marcas de nossa resistência. Mas é preciso ter consciência de que isso não basta. A nossa luta é no campo das políticas públicas, pois esta é a única maneira concreta de universalizarmos o acesso de todo o povo à educação. Da mesma forma, é preciso incluir o debate da educação do campo no contexto geral da educação.

A educação do campo se identifica pelos seus sujeitos. É preciso compreender que por trás da indicação geográfica e da frieza de dados estatísticos existe um povo brasileiro que vive neste lugar desde as primeiras relações sociais; pessoas de diferentes idades, famílias, comunidades, organizações, movimentos sociais. A perspectiva da educação do campo é a de educar este povo, estas pessoas que trabalham no campo, para se articularem, se organizarem e assumirem a condição de sujeitos na direção de seu destino.

Ele ficou profundamente abatido. Seu "eu" não governava seus pensamentos. Pensava muito e sem qualidade. Este é um grande problema. $\mathrm{O}$ acesso de pensamento é o grande carrasco da qualidade de vida do ser humano (CURY, 2002. P. 43).

Contudo, este nosso movimento preza pelo fim da visão estreita de educação como preparação de mão-de-obra e a serviço do mercado. A população deve participar diretamente da construção do projeto educativo; aprender a pensar sobre a educação que realmente interessa como seres humanos, sujeitos de diferentes culturas, classe trabalhadora do campo, sujeitos das transformações necessárias, em nosso país, como cidadãos do mundo.

Grupos pertencentes às comunidades quilombolas são aquelas pessoas que sentem na própria pele os efeitos desta realidade perversa, mas que inconformados, lutam para continuar sendo agricultores. Apesar de um modelo de agricultura cada vez mais excludente, lutam pela terra, reforma agrária, melhores condições de trabalho, identidade própria desta herança, pelo direito de continuar a ser indígena em terras demarcadas e em identidades e direitos sociais respeitados e tantas outras resistências culturais e políticas.

São pequenos agricultores quilombolas, povos indígenas, pescadores camponeses, assentados, reassentados, ribeirinhos, povos da floresta, caipiras, lavradores, roceiros, sem terra, agregados, caboclos, meeiros, assalariados rurais e outros grupos mais. 
Um dos maiores desafios para as comunidades quilombolas é inserir na escola matrizes pedagógicas ligadas às práticas sociais; combinar estudo com trabalho, com cultura, organização coletiva, postura de transformar o mundo. Prestando atenção às tarefas de formação específicas do tempo e do espaço escolar; pensar a escola a partir do seu lugar e de seus sujeitos, dialogando sempre com a realidade mais ampla e com as questões de educação, da humanidade. A escola do campo terá uma identidade própria, mas vinculada a processos de formação bem mais amplos, que não iniciam e terminam nela mesmas e que ajuda na tarefa grandiosa de fazer a terra ser mais do que terra. $A$ educação do campo também se verifica na valorização dos educadores. Em vários lugares eles têm sido importantes colaboradores em especial nas escolas, têm estado à frente de muitas lutas pelo direito à educação.

Saber que não posso passar despercebido pelos alunos, e que a mesma maneira como me percebam me ajuda ou desajuda no cumprimento de minha tarefa de professor, aumento em mim os cuidados com o meu desempenho (FREIRE, 2002, P. 96).

Educador é aquele cujo trabalho principal é o de fazer pensar a formação humana, seja ela na escola, na família, na comunidade, nos movimentos sociais, educando as crianças, jovens, os adultos, ou os idosos. Nesta perspectiva, todos somos de alguma forma educadores, mas isto não tira a especificidade desta tarefa: nem todos temos como trabalho principal educar as pessoas e conhecer a complexidade dos processos de aprendizagem e de desenvolvimento do ser humano em suas diferentes gerações. Por isso, defendemos com tanta insistência a necessidade de políticas e de projetos de formação dos educadores do campo. Sabemos que boa parte deste ideário que estamos construindo é algo novo em nossa própria cultura e que há uma nova identidade de educador que pode ser cultivada a partir deste movimento por uma educação do campo. Cultivar esta identidade e lutar por ela é uma das tarefas que assumimos como participantes deste movimento.

O grande problema que se coloca ao educador de opção democrática é "como trabalhar no sentindo de fazer possível que a necessidade do limite seja assumida eticamente pela liberdade" (FREIRE, 2002. P.105). 
Conforme a Resolução nº 8 (BRASIL, 2012, não paginado), em seu art. 9०, define que:

\author{
A Educação Escolar Quilombola compreende: \\ I - escolas quilombolas; \\ II - escolas que atendem estudantes oriundos de ter- \\ ritórios quilombolas. \\ Parágrafo Único Entende-se por escola quilombola \\ aquela localizada em território quilombola.
}

Uma escola do campo não é, afinal, um tipo diferente de escola, mas sim é a escola reconhecendo e ajudando a fortalecer os povos do campo como sujeito social, que também podem ajudar no processo de humanização do conjunto das sociedades, com suas lutas, sua história, seu trabalho, seus saberes, sua cultura, seu jeito. Também pelos desafios da sua relação com o conjunto da sociedade. Ajudar a construir escolas do campo é fundamental, bem como construir os povos do campo como sujeitos organizados e em movimento. Somente as escolas construídas política e pedagogicamente pelos sujeitos do campo conseguem incorporar os valores e as formas de organização e de trabalho dos povos do campo. As pessoas passam a acreditar que para ficar no campo não precisam mesmo de "muitas letras".

Quando falo em educação como intervenção, me refiro tanto à que aspira a mudanças radicais na sociedade, no campo da economia, das relações humanas da propriedade, do direito ao trabalho, à terra, à educação, à saúde, quanto a que, pelo contrário, racionalmente pretende imobilizar a História e manter a ordem injusta (FREIRE, 2002. P. 109).

São os desafios do campo em movimento que multiplicam as lutas sociais por educação. Por sua vez, são estas lutas que vão ajudando a tornar consciente este direito, transformarão aos poucos este direito também em dever que então se consolida em modo de vida e visão de mundo. A escola deve ser vista como uma das dimensões do processo de formação das pessoas, e não como algo especial, para cuja obtenção tudo o mais deve ser abandonado.

Sair do campo para estudar, ou estudar para sair do campo não é uma realidade inevitável, assim como não são imutáveis as características, marcadamente alheia à cultura do campo. Hoje cada nova escola 
que se conquista em um assentamento ou acampamento, cada jovem ou adulto sem terra que se alfabetiza, cada curso de formação que se cria para formar os trabalhadores da terra e do movimento ajuda a construir a identidade do sujeito do campo. "A prática educativa do professor ou da professora é o que diz respeito à força, às vezes maior do que pensamos da ideologia". (FREIRE, 2002, P. 125).

A educação do campo é um conceito cunhado com a preocupação de se delimitar um território teórico. Nosso pensamento é defender o direito que uma população tem de pensar o mundo a partir do lugar onde vive, ou seja, da terra em que pisa, melhor ainda, a partir da realidade concreta. Quando pensamos o mundo a partir de um lugar onde não vivemos, idealizamos um mundo, vivemos um não-lugar. Isso acontece com a população do campo quando pensa o mundo e, evidentemente, o seu próprio lugar a partir da cidade. Esse modo de pensar idealizado leva ao estranhamento de si mesmo, o que dificulta a construção da identidade condição fundamental da formação cultural. A Constituição de 1988 foi resultado de uma luta popular que emergiu contra a ditadura e restabeleceu a democracia. Nesse contexto, a luta pela terra possibilitou a formação de uma concepção democrática de educação, em que os seus protagonistas propuseram e levaram a cabo o direito de ter uma escola que contribui de fato para o desenvolvimento do campo.

A identidade da escola do campo é definida pela
sua vinculação às questões inertes a sua realidade,
ancorando-se na temporalidade e saberes próprios
dos estudantes, na memória coletiva que sinaliza fu-
turos, na rede de ciência e tecnologia disponível na
sociedade e nos movimentos sociais em defesa de
projetos que associam as soluções exigidas por essas
questões à qualidade social da vida coletiva do país
(CF, 1988).

O primeiro desafio que se verifica é perceber qual educação está sendo oferecida ao meio rural e que concepção de educação está presente nesta oferta. Ter isso ajuda na forma de expressão e implantação de tal proposta. A educação do campo precisa ser uma educação específica e diferenciada, isto é, sobretudo deve ser educação, no sentido amplo de processo de formação humana, que constrói referências culturais e políticas para a intervenção das pessoas e dos sujeitos sociais na realidade, visando a uma humanidade mais plena e feliz. 


\section{Grupo de Tradições Culturais Samba de Cumbuca da comunidade quilombola de Salinas município de Campinas do Piauí}

Os traços de identidade de uma comunidade, como processo de construção da sociedade atual, são marcados pela sua trajetória de luta. As tradições culturais na comunidade quilombola de Salinas estão estritamente estruturadas nos seus antepassados, que marcaram profundamente a história da civilização local.

Miranda (2000) explica que a ideologia relacionada à identidade cultura vem modificando-se ao longo do processo civilização. Desde aquele sujeito do iluminismo entendido como tal unificado desde seu nascimento, dotado da capacidade de razão, consciência e ação, passando também pela ideia mais recente do indivíduo que se forma nas relações interpessoais. Com isso, pode-se dizer que a identidade do indivíduo é uma forma de expor sua origem, cultura, enfim, características que explica com clareza quem é a pessoa, sua história, etc.

Em relação às tradições Culturais da Comunidade Quilombola de Salinas do município de Campinas do Piauí, o coordenador da comunidade relatou o seguinte:

Os "troncos velhos", antepassados que já se foram
desta vida material, relatavam que cantavam e dan-
çava o samba de cumbuca de volta para pegar o sol
com a mão. As brincadeiras eram feitas pela madru-
gada e aconteciam até o sol nascer. O repertório vai
passando dos pais para os filhos. O jeito de danças
mantém a sua essência. Um jeito singular que pode
ser confundido com rústico, bem diferente do samba
das escolas, mas, ainda assim, pode ser sentido como
pertencente às raízes deste (FERREIRA).

Ferreira reforça que não se sabe os nomes exatos porque esses registros se perderam, mas por aqui todo mundo é descendente de antigos escravos. Imaginamos que a tradição do samba de cumbuca veio das senzalas existentes nas fazendas.

Hoje, assim como no passado, os ensinamentos do samba vão passando dos gritos para os jovens e crianças. O grupo se forma em um processo dinâmico, mesmo sem estrutura ou recursos para oferecer maior interação com esta manifestação cultural.

Nesse sentido, conforme os relatos do coordenador da comunidade, 
O grupo de tradições culturais samba de cumbuca de volta surgiu na vida da história da comunidade, quando seis mulheres negras escravizadas chegaram ao quilombo volta e ali começaram a expressar sua identidade cultural. Dizem os mais velhos da comunidade que essas mulheres negras, após um longo dia de trabalho, passavam a noite tocando samba de cumbuca: uma mistura de dança, canto e som tirado das mesmas cabeças que utilizavam para carregar água. (FERREIRA).

Essa expressão cultural tornou-se importante para construir a história desde povo, pois todos os habitantes da comunidade quilombola de Salinas são descendentes daquelas mulheres escravizadas. O samba de cumbuca de volta percorreu a história, até os dias de hoje, através da interação com a oralidade de uma continuidade de gerações, tornando-se um tesouro de valor inestimável para os seus descendentes atuais, que continuam a tradição de tocar, dançar e ensinar seus dias.

Sobre as tradições culturais da comunidade, o coordenador destaca:

O grupo de Tradições Culturais Samba de Cumbuca tem como missão desenvolver e apoiar iniciativas com a intencionalidade de desencadear processos que oportunizem a comunidade condições para viver imortalizar e salvaguardar manifestações culturais e identidades dos povos negros de descendência africana no Brasil-Piauí, sob o fundamento de cultura como produção de história, de economia, como construção simbólica e direito a cidadania. O grupo tem desenvolvido várias ações que salvaguarda afro-brasileira, como participar de vários eventos regionais e estaduais como: A feira piauiense de produtor da Reforma Agrária e comunidades Quilombola, (FERAPI) conferencias Estaduais e Nacionais de promoção da igualdade Racial, Festival Nacional de Folguedos dentre outras, atualmente o grupo teve seu projeto (Ponto de Cultura Cumbaca de Quilombo) aprovado pelo Ministro da Cultura e Fundação Cultural do Estado projeto este que tem como meta trabalhar cultura e educação em parceria com a escola da comunidade, e foi contemplado no premio de culturas populares da Secretaria Nacional da Diversidade. Em 2007 foi documentado pelo Ministério da Cultura no Inventário Nacional de Referencias Culturais, sendo o primeiro do estado, daí foi produzido o documentário Cumbu- 
ca do quilombo que conta a história da comunidade volta, assistido por todo o Brasil e sendo premiado na mostra afro olhar no festival de Atibaia em São Paulo e exibido em 21 cines tele do Brasil (FERREIRA).

Discutir e descrever o processo de desenvolvimento da capacidade física, intelectual e moral do ser humano é oportuno e bastante interessante. A cultura é um processo permanente e homens e mulheres são vistos como seres dinâmicos, capazes de enriquecer continuamente. O dinamismo da sociedade é importante para alcançar os objetivos ao longo da vida. $O$ sistema educativo tem o dever de assegurar o processo cultural e facilitar a sua continuidade. Assim na educação, a psicologia educacional é determinante para alcançar muitos objetivos como: equipar os profissionais da educação com técnicas modernizadas para facilitar a busca do resgate dos costumes de grupos e comunidades como a mencionada para ajudar a compreender melhor o papel da sociedade no processo educativo e entender os traços de identidade de um povo.

O registro típico da mutação do ensino e da cultura é retratado nas entrevistas realizadas ao povo ladakhiano quando em sua língua originaria é inserida um modelo padrão da linguagem advinda de outra origem para facilitar o entendimento do processo de globalização das sociedades em rede. Tanto a música bem como a dança que se encontravam arraigadas nos costumes desapareceram com o surgimento do livre comércio e a mecanização da mão-de-obra. Surgiram também, em meio àquela cultura de efeitos nocivos, doenças abrangência de favelas e várias formas de violência, infectando o processo sociocultural.

Diante disso, se percebe que a educação traz, sim, desenvolvimento, ampliação do conhecimento, estímulo à criatividade e que, para o ser humano, implica a crescente apropriação pelo homem de sua posição no contexto de libertação e limitações de uma sociedade particular centralizada e autoritarista.

Paulo Freire (2005, p. 207) em sua obra Pedagogia do Oprimido, afirma que "o que pretende a ação cultural dialogada, cujas características acabamos de analisar, não pode ser o desaparecimento da dialeticidade permanência-mudança, mas superar as contradições antagônicas de que resulta a liberação dos homens". A proposta educacional de qualquer país deve ser pensada com e para o povo, a fim de que aconteça um crescimento econômico de forma estruturada e assim o desenvolvimento econômico global seja real. 
O campesinato é um grupo social que, além das relações sociais em que está envolvido, tem um triunfo do território (FERNANDES; MOLINA, 2005).

De fato, isso é divergente da realidade vivida tanto no Brasil como na comunidade quilombola Salinas. Na verdade, as informações dificilmente chegam ao conhecimento de grupos sociais isolados, que cultivam sua identidade cultural originária, sendo o processo de educação o principal responsável para não deixar que isso aconteça, procurando adaptar cultura e educação, já que ambas se completam.

Em algumas entrevistas realizadas com Ferreira (coordenador dos grupos quilombolas da comunidade Salinas do município de Campinas do Piauí), ele mostra sua similaridade com o modo de vida nas aldeias ladakhinos, quando ele relata:

Nossa cultura foi perdida; nosso espaço invadido. As lembranças de uma vida "dura", mas alegre emociona, quando traz à tona um exemplo de vida em coletividade embalada por muita música, dança, cantorias, rezas, crendices populares, ou seja, valores de suma importância tomados como forma de vida (FERREIRA).

Hoje se fala em resgate de cultura, é bom lembrar o passado, buscando um pouco do que se viveu, porém muita coisa se perde, nunca é do mesmo jeito, deixam coisas de valores, "morrem" as lembranças, as amizades, as forças a alegria de viver.

Não só Ferreira, bem como muitos membros do grupo Samba de Cumbuca, que estavam presentes na entrevista realizada demonstraram a mesma preocupação, pois o trabalho é dado de forma individual, a competitividade entre povos é clara e assustadora, cada um busca o melhor para si, desconsiderado a coletividade.

Preza a Constituição Federal promulgada em 1988 na era de Sarney que nós, seres humanos, somos dotados de direitos e deveres, conforme os relatos dos artigos a seguir:

Art. $5^{\circ}$ : Todos somos iguais perante a lei, sem distinção de qualquer natureza. Dando a homens e mulheres oportunidades para competitividade ao mercado de trabalho; [...]

Art. $215^{\circ}$ : O estado garantirá a todos pleno exercício dos direitos culturais e acesso às fontes de cultura na- 
cional, e apoiará e incentivará e valorização e difusão das manifestações culturais. (BRASIL, 1998)

Observa-se que falta muito para se concretizar de fato essa integração, sem que haja "educação" e "cultura" para enfrentar os obstáculos e buscar melhorias. Alguns sofrem com a falta de acesso à informação e qualificação da mão-de-obra para o mercado de trabalho, sendo estes induzidos a biografar suas histórias e viver o presente que lhes é oferecido, deixando morrer aos poucos as formas de vivências em comunidades rurais ou interioranas e menosprezando seu espaço, sua história, seu passado. A cultura deve ser pensada como um conjunto de tradições repassadas aos seus descendentes para que haja uma integração coletiva e familiar de traços de identidades de um grupo ou comunidade remanescentes de ancestrais que valorizam suas manifestações.

\section{Considerações finais}

A sociedade é formada por pessoas que pertencem a grupos étnico-raciais distintos, que possuem cultura e história próprias, igualmente religiosas e que em conjunto constroem, na nação brasileira, sua história. O conhecimento e a valorização da história dos povos africanos e da cultura afro-brasileira tiveram significativa importância na construção histórica e cultural brasileira.

Ficou evidente nas análises realizadas que a comunidade quilombola de Salinas do município de campinas do Piauí deseja que a cultura se torne elemento de reconstrução de identidade. Pois reconstruir a identidade nessas circunstâncias significa reconstruir a autoestima e autoimagem positiva, que são condições para proporcionar formas de organização que constituem a base de sustentação de programas de inclusão, capacitação e geração de renda em projetos autossustentáveis.

Constatou-se que é necessário eliminar conceitos, ideias, comportamentos veiculados pela ideologia do branqueamento, pelo mito da democracia racial, que tanto mal fazem a negros e brancos, por meios de questionamentos e análises críticas. Além disso, devem-se articular junto aos professores não familiarizados com a análise das relações étnico-raciais e sociais com o estudo de história e cultura afro-brasileira e africana, incidir informações e subsídios que lhes permitam formular concepções não baseadas em preconceitos e construir ações respeitosas; estimular o diálogo, via fundamental para entendimento entre 
diferentes com a finalidade de negociações, tendo em vista objetivos comuns, visando a uma sociedade justa.

Observou-se, na comunidade em análise, a falta de condições para professores e alunos pensarem, decidirem, agirem, assumindo responsabilidade por relações étnico-raciais positivas, enfrentando e superando discordâncias, conflitos, contestações, valorizando os contrastes das diferenças da oralidade da arte como a dança, marcas da cultura de raiz africana. Diante disso, deve-se ter relativo cuidado para que se dê um sentido construtivo à participação dos diferentes grupos sociais, étnico-raciais aos elos culturais e históricos, às alianças sociais, efetivando essa participação aos grupos do movimento negro, bem como da comunidade inserida na escola, sob a coordenação dos profissionais, na elaboração de projetos-pedagógico que contemple a diversidade étnico-racial.

Contudo, o povoado de Salinas do município de campinas do Piauí, como comunidade quilombola, apresenta uma cultura com sentido mais amplo, quando abrange a totalidade do modo de vida de um povo. A cultura de um povo não inclui só artes e técnicas, mas também crenças, costumes, invenções, modo de preparar os alimentos, de se vestir, enfim, todos os valores espirituais e materiais que estão presentes na vida dessas pessoas. Todos esses conhecimentos são acumulados e transmitidos de geração a geração, por meio da linguagem. Assim a geração mais velha transmite à mais nova inúmeras informações e experiências coletivas acumuladas.

Diante disso, percebe-se que embora a Comunidade Quilombola Salinas tenha uma cultura forte, pautada na conservação das tradições de geração para geração, é perceptível a necessidade de trabalhar o processo interativo coletivo e familiar na comunidade, bem como o reconhecimento de que a cultura da comunidade e a cultura da escola devem dialogar, para que aconteça uma educação de pertencimento, valorização da cultura e um desempenho na aprendizagem que expresse as diferenças como força coletiva de quilombolas.

\section{Referências}

BESSA Silvia, Reportagem: Quilombola - Os direitos negados de um povo / Diário de Pernambuco / Brasil 2010.

BRASIL. Lei $n^{\circ} 10.639$, de 9 de janeiro de 2003. Altera a lei $n^{\circ} 9.394$, de 20 de dezembro de 1996, que estabelece as diretrizes e bases da 
educação nacional, para incluir no currículo oficial da rede de ensino a obrigatoriedade da temática "História e Cultura Afro-brasileira", e dá outras providências. Diário Oficial da União, Brasilia, DF, 10 jan, 2003. Disponível em: http://www.planalto.gov.br/ccivil_03/leis/2003/l10.639. htm. Acesso em: 05 nov. 2018. .

BRASIL. Lei no 9.394, de 09 de janeiro de 1996. Estabelece as Diretrizes e Bases da Educação Nacional. Diário Oficial da União, Brasilia, DF, 23 dez. 1996. Disponível em: https://www.planalto.gov.br/ccivil_03/Leis/ L9394.htm. Acesso em: 28 jan. 2018.

BRASIL. Constituição da República Federativa do Brasil de 1988. Diário Oficial da União, Brasilia, DF, 5 out. 1988. Disponível em: http://www. planalto.gov.br/ccivil_03/constituicao/constituicaocompilado.htm. Acesso em: 28 jan. 2018.

BRASIL. Ministério da Educação (MEC). Conselho Nacional de Educação. Resolução no 08, de 20 de novembro de 2012. Parecer CNE/CEB no 16 de 2012. Define diretrizes curriculares nacionais para educação escolar quilombola na educação básica. Diário Oficial da União, Brasília, DF, 20 nov. 2012.

BRASIL. Instrução Normativa N. 16, DE 24 de março de 2004. Regulamenta o procedimento para identificação, reconhecimento, delimitação, demarcação e titulação das terras ocupadas por remanescentes das comunidades dos quilombos de que trata o art. 68 do Ato das Disposições Constitucionais Transitórias. Brasília, 2004. Disponível em: http://www. incra.gov.br/pt/institucionall/legislacao--/atos-internos/instrucoes/file/ 169-instrucao-normativa-n-16-24032004. Acesso em 08/01/2018 às 19:00.

CURY, Augusto. Nunca Desista de seus Sonhos, Rio de Janeiro, 2002.

FERNANDES, Bernardo Maçando. MOLINA, Mônica Castagna. O campo da Educação do Campo. IN: MOLINA, Mônica Castagna e JESUS, Sonia M.S.A. (Orgs.). Por uma educação do campo - contribuições para a construção de um projeto de Educação do Campo. 2. ed. Brasília, DF: Articulação Nacional “Por uma Educação do Campo”, 2005.

FREIRE, Paulo. Pedagogia da Autonomia, Saberes necessários a prática educativa. Rio de Janeiro, 2002.

FREIRE, Paulo. Pedagogia do Oprimido, Editora paz e terra. Rio de Janeiro, 2005. 
GOMES, N. L. Currículo, corpo e identidade. In:CONGRESSO NACIONAL DE REORIENTAÇÃO CURRICULAR, 2., 2000, Blumenau. Anais [...] Blumenau: Secretaria Municipal de Educação, 2000.

HALL,Stuart. Quem precisa de identidade? In: SILVA, Tomaz Tadeu da (org.). Identidade e diferença: a pespectiva dos estudos culturais. Petrópolis: Vozes, 2000. p. 103-133. Fundação Ford: www.fordfound.org; Acesso em 08/01/2018 às 19:00.

JACCOLD, Luciana. As políticas públicas e a desigualdade racial no Brasil: 120 anos após a abolição. Brasília, Editora do IPEA, 2008. P. 55.

LIMA, JORGE. A divisão de cristo. In: Mendes, Murilo; LIMA,jorge de. Tempo e eternidade. Porto Alegre: Livraria do globo,1935, p,41.

BRASIL. Ministério de Desenvolvimento Social e Combate à Fome. Conselho Nacional de Assistência Social. Política Nacional de Assistência Social. Brasília, 2007.

MIRANDA, Shirley Aparecida de. Educação escolar quilombolas em Minas Gerais: entre ausências e emergências. Revista Brasileira de Educação, v. 17, n. 50, mai/ago. 2000. p. 369 - 383. Disponível em: http:// www.scielo.br/pdf/rbedu/v17n50/v17n50a07.pdf. Acesso em: 15 jun. 2018

PERUTTI, Daniela Carolina. Os Quilombolas e o Placar das Titulações. Fórum (periódico) V. 80. São Paulo, 2009.

PNDS - PESQUISA NACIONAL DE DEMOGRAFIA E SAÚDE DA CRIANÇA E DA MULHER. Banco de dados. 2008. Disponível em: http:// bvsms.saude.gov.br/bvs/pnds/banco_dados.php. Acesso em: 03 ago. 2018.

THEODORO, Mario. As políticas públicas e a desigualdade racial no Brasil: 120 anos após a abolição. Brasília,Editora do IPEA, 2008. p. 19.

Recebido: Setembro/2018

Aceito: Dezembro/2019 